\title{
Atuação da sociedade civil no enfrentamento dos efeitos da COVID-19 no Brasil
}

\section{Carolina Andion 1}

1 Universidade do Estado de Santa Catarina / Programa de Pós-Graduação em Administração, Florianópolis / SC - Brasil

Este texto discute a atuação da sociedade civil na ação pública para o enfrentamento das consequências da pandemia da COVID-19 no Brasil. Partindo de uma lente pragmatista de análise, examinamos as ações coletivas da sociedade civil no combate aos efeitos da COVID-19, ressaltando suas características, seus alcances e seus limites na governança dessa crise. Para tanto, em primeiro lugar, por meio de um levantamento documental, analisamos a mobilização recente da sociedade civil e, depois, examinamos a realidade da cidade de Florianópolis, a qual acompanhamos mais de perto, mediante pesquisa de campo. Os resultados permitem construir um panorama da atuação dessas "redes invisíveis" e lançar pistas sobre as consequências e os desafios dessa atuação. As conclusões chamam a atenção para a necessidade de explorar mais a fundo o papel, as possibilidades e os dilemas da sociedade civil na produção de uma "governança experimentalista" em resposta aos inúmeros desafios impostos pela crise causada por essa pandemia no âmbito local.

Palavras-chave: COVID-19; sociedade civil; ação pública; governança; experimentação democrática.

\section{Acción de la sociedad civil para enfrentar los efectos de la COVID-19 en Brasil}

Este texto analiza el papel de la sociedad civil en la acción pública para enfrentar las consecuencias de la pandemia de COVID-19 en Brasil. Partiendo de una perspectiva de análisis pragmática, examinamos las acciones colectivas promovidas por los actores de la sociedad civil en Brasil en la lucha contra la COVID-19, destacando sus características, su alcance y sus límites en la gobernanza de esta crisis. Para ello, primero, a través de análisis documental, investigamos la reciente movilización de la sociedad civil en el país y, en un segundo momento, examinamos la realidad de la ciudad de Florianópolis, que seguimos más de cerca, a través de investigación de campo. Los resultados permiten construir una visión general de la acción de estas "redes invisibles" y proporcionar pistas sobre sus consecuencias y desafíos. Las conclusiones llaman la atención sobre la necesidad de explorar más a fondo el papel, las perspectivas y dilemas de la sociedad civil en la producción de una "gobernanza experimentalista" en respuesta a los numerosos desafíos planteados por la crisis causada por esta pandemia a nivel local.

Palabras clave: COVID-19; sociedad civil; acción pública; gobernanza; experimentalismo democrático.

\section{Civil society mobilization in coping with the effects of COVID-19 in Brazil}

This text discusses the role of civil society in public action to face the consequences of the COVID-19 pandemic in Brazil. Based on a pragmatic approach, the study examines the collective actions promoted by civil society actors in Brazil, highlighting the characteristics, scope, and limits in the governance of this crisis. The study uses documental analysis to observe the recent mobilization of civil society in the country and field research to explore the reality of the city of Florianópolis. The results offer an overview of the performance of "invisible networks" of civil society actors, pointing out the challenges and outcomes of their actions. The findings suggest the need for further studies exploring the role, perspectives, and dilemmas of civil society in the production of "experimentalist governance" in response to the numerous challenges posed by the pandemic at the local level.

Keywords: COVID-19; civil society; public action; governance; democratic experimentalism.

"O essencial é invisível aos olhos". Antoine de Saint-Exupéry 


\section{INTRODUÇÃO}

A análise das respostas da sociedade civil brasileira frente às consequências da COVID-19 pode ajudar a compreender melhor as características dessa atuação sobre os problemas públicos, assim como sua contribuição e seus limites, no âmbito da administração pública. Isso porque a situação sem precedentes imposta pela pandemia, em vários países, se configura como uma importante situação de incerteza que abre possibilidades objetivas de repensar e reinventar as formas clássicas de governar, de praticar governança pública, e a própria atuação da sociedade civil.

A pandemia da COVID-19 pode ser encarada como uma "situação de prova", 1 um momento de bifurcação que abre possibilidades para questionar o status quo e reinventar instituições e práticas antes estabelecidas. Tal "situação problemática" também impõe novas formas de coordenação e de governança para responder aos inúmeros problemas públicos nas áreas de saúde, economia, proteção social, política, entre outras. Numa situação como essa, não há como definir objetivos e métricas a priori, os quais precisam ser constantemente revistos, tomando por base diferentes expertises e práticas em curso para promover aprendizagem, adaptação e soluções efetivas para os diversos e complexos desafios que se impõem à administração pública e que exigem respostas intersetoriais e interdisciplinares.

Embora crítica, a situação urgente imposta pela pandemia pode gerar experimentações e novos meios de interface entre sociedade civil, Estado e administração pública. Compreender tais processos é premente na situação brasileira atual, já que o país se coloca como epicentro da pandemia - com aumento exponencial dos casos e das mortes pelo coronavírus, que se espalha para o interior - e tem sido internacionalmente reconhecido como um dos piores exemplos de governança da crise. Isso se dá em função de vários aspectos, ${ }^{2}$ como: (1) colapso gradativo dos sistemas de saúde de vários estados; (2) falta de coordenação, de comunicação e os conflitos recorrentes entre os poderes e os níveis de governo; (3) profunda desigualdade territorial, de renda, de condições de vida e de acesso aos serviços públicos de saúde e de proteção social; (4) formalismo, déficit de cobertura e falta de orçamento para as políticas públicas de saúde e de proteção social; (5) escalada do autoritarismo, falta de transparência e polarização política, amplificadas pela posturas do presidente e do alto escalão de seu governo frente à pandemia.

Diante desse cenário, partimos de algumas indagações: como se dá e quais são as características da atuação da sociedade civil no combate aos efeitos da COVID-19 no Brasil? Quais são os alcances e os limites dessa atuação? Quais são suas contribuições para a governança da crise? Em que medida essa atuação é promotora de processos de "experimentações democráticas"? Essas são as perguntas a que nos propomos responder, de forma exploratória, nas seções a seguir.

Para tanto, parte-se do debate sobre a relação entre Estado e sociedade civil, problematizando o papel desta na ação pública. As perspectivas predominantes nesse debate são discutidas ao expor as

\footnotetext{
${ }^{1}$ Como destaca Chateauraynaud (2011, p. 16), o conceito de prova é central no pragmatismo e na sociologia pragmática. A situação de prova constitui-se em um momento de incerteza e indeterminação na vida e na trajetória dos atores, quando as possibilidades de uma mudança de estado e das relações são reveladas no fluxo da ação. Nesses momentos, as pessoas precisam provar suas competências para agir, designar, qualificar, julgar ou justificar algo ou alguém. Trata-se de um momento de incerteza e indeterminação por excelência, mas também é uma ocasião para chegar a um novo acordo sobre o estado dos seres (pessoas ou coisas).

${ }^{2}$ Diversos artigos recentes publicados na mídia têm sido escritos por colegas do campo de públicas ressaltando esses problemas e não serão discutidos amplamente aqui por uma questão de foco. Para acessar um dos mais recentes, ver Abrucio e Teixeira (2020).
} 
diferenças entre as formas de governança postuladas e a "governança experimentalista" adotada neste estudo. Em seguida, construímos um panorama geral da atuação da sociedade civil no combate à pandemia no país, examinando suas principais características e efeitos. Isso é realizado pela análise de dados secundários veiculados em relatórios e plataformas digitais produzidos por instituições de referência que congregam informações sobre essa atuação. ${ }^{3}$

Na terceira seção, por meio de estudo de caso descritivo e interpretativo (Godoy, 2006), examinase mais de perto a mobilização da sociedade civil de Florianópolis frente aos efeitos da COVID-19 na cidade. $\mathrm{O}$ estudo foi realizado por levantamento de dados secundários e primários, mediante a cartografia da arena pública. ${ }^{4}$ Isso permitiu identificar 44 iniciativas da sociedade civil que atuam no combate aos efeitos da pandemia em Florianópolis, bem como observar mais de perto algumas dessas experiências e acompanhar a discussão pública sobre o tema, com a participação da autora em debates sobre a questão em diferentes cenas da cidade. ${ }^{5}$ Para concluir, são apresentadas considerações finais sobre as características da atuação da sociedade civil e os fatores que estimulam ou dificultam o exercício de uma governança experimentalista em resposta a crise imposta pela pandemia, com base no cruzamento dos achados da pesquisa.

\section{PROBLEMATIZANDO 0 DEBATE SOBRE A ATUAÇÃO DA SOCIEDADE CIVIL NA AÇÃO PÚBLICA}

Tradicionalmente, observa-se o predomínio, tanto na prática quanto nas teorias da administração pública, de uma concepção estadocêntrica e tecnocrática, na qual o governo se coloca como agente principal ou exclusivo do ato de governar. Nas últimas décadas, entretanto, parece haver consenso quanto à necessidade de repensar tal concepção, diante dos desafios impostos pelo manejo de problemas públicos cada vez mais complexos e desafiadores. Com isso, emerge uma abordagem multicêntrica ou multiatores que considera que o escopo do governar vai muito além da ação do governo. A ideia de governança se impõe, convidando a olhar para as diversas formas de interação e de coordenação conjunta entre sociedade civil e poder político, ressaltando a multipolaridade dos poderes instituídos, sua fluidez e descentralização (Gaudin, 2002; Salamon, 2011; Levi-Faur, 2012). Embora haja consenso nessa (re)interpretação, a governança se torna hoje uma palavra guarda-chuva,

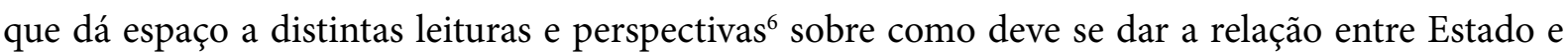
sociedade civil e qual é o papel desta na ação pública.

Uma primeira perspectiva, bastante influente no Brasil, se ancora no paradigma racionalista e na

\footnotetext{
${ }^{3}$ As referências utilizadas são citadas ao longo da análise na terceira seção.

${ }^{4}$ A cartografia da arena pública foi feita por meio do Observatório de Inovação Social de Florianópolis, plataforma on-line colaborativa construída pela pesquisa na qual este estudo se insere (www.observafloripa.com.br) e implementada em 2017. Para levantamento dos dados, de abril a junho de 2020 , foram usados outros mapeamentos já realizados na cidade e que foram complementados por aplicação de questionários e de observação junto às iniciativas da sociedade civil que atuam no combate aos efeitos da pandemia. Para maior detalhamento do enfoque teórico-analítico e metodológico aplicado na pesquisa, ver Andion, Alperstedt, e Graeff, (2019, 2020).

${ }^{5}$ No dia 3 de abril, a autora participou de uma conversa on-line com a secretária de Assistência Social sobre a atuação da prefeitura em relação à pandemia. No dia 15 do mesmo mês, participou de forma remota de debate público na Câmara dos Vereadores com a secretária de Assistência Social sobre as ações de enfrentamento da pandemia da COVID-19 na cidade. No dia 27 de maio, participou como moderadora e debatedora em seminário sobre a atuação das organizações da sociedade civil (OSCs) no combate à COVID-19, e, em 2 de junho, da assembleia do Fórum de Políticas Públicas de Florianópolis (FPPF), espaço de articulação de coletivos, movimento sociais, usuários e organizações da sociedade civil que atuam nos conselhos de políticas públicas.

${ }^{6}$ Por uma questão de foco, não adentraremos o amplo debate sobre governança pública, concentrando-nos nas principais correntes que discutem as ações coletivas da sociedade civil na esfera pública (Cefaï, 2007) e explorando sua interface com a governança. Para maior aprofundamento no debate sobre governança e suas diferentes perspectivas, ver Gaudin (2002) e Levi-Faur (2012).
} 
teoria de mobilização de recursos (McCarthy \& Zald, 1977), relacionando-se ao conceito de terceiro setor e/ou à noção de governo da terceira parte (Salamon, 2011). Inserida no movimento de reinvenção do Estado, diante das reformas inspiradas no New Public Management, tal perspectiva interpreta a sociedade civil como um enclave complementar e dependente da ação governamental. A noção de "interdependência" (Salamon, 1995) é colocada como alternativa para ampliar a eficiência do Estado e diminuir seus custos. A governança aqui ocorre pelo controle do principal (governo) em relação ao agente, que são as organizações da sociedade civil (OSCs), as quais assumem o papel de prestar serviços e/ou produzir bens públicos. Muitos estudos, entretanto, têm exposto os limites de tal perspectiva, que muitas vezes se traduz na prática pela cooptação da sociedade civil, levando a uma perda de autonomia na sua atuação e a tornando mais funcional do que transformadora (Meyer \& Maier, 2015).

Uma segunda concepção, também bastante influente na América Latina e tributária do paradigma dos novos movimentos sociais, interpreta os atores da sociedade civil como agentes de transformações no quadro social e político mais amplo. Os estudos amparados nessa corrente buscam evidenciar a capacidade de mobilização e incidência desses grupos na criação de novas identidades coletivas e de direitos, tomando o conflito como noção-chave (Cohen \& Arato, 1994). Aqui, a influência na governança se dá por meio da pressão, do controle social e de lutas políticas e simbólicas instauradas pelos movimentos sociais em diferentes campos de causa.

Essas duas leituras das relações entre sociedade civil e Estado, de certa forma opostas, dominaram o debate até os anos 1980 e foram incorporadas nos modelos de análise do campo que ora supunham a sociedade civil como parceira, ora como adversária do governo (Young, 2000).

Uma terceira perspectiva, mais recente, dialoga com a teoria da mobilização política (Tarrow, 2009) e promove uma articulação entre as duas primeiras correntes. Os estudos nessa linha ampliam o debate sobre a importância da participação da sociedade civil e do controle social exercido por ela, considerando as múltiplas formas de representação política, de controle social e de legitimidade no contexto das democracias (Almeida, 2014). Esse debate sobre as instâncias participativas (IPs) se ampliou no Brasil e na América Latina nos últimos anos, evidenciando alcances e limites da participação e dos processos de deliberação, que envolvem a sociedade civil nos sistemas de governança, diante da crise das democracias representativas.

Sem desconsiderar a importância de cada uma dessas correntes, pode-se afirmar que, em todas elas, se parte de uma ideia fundadora de que a sociedade civil e o Estado são entes/enclaves separados. As concepções de política, de governança e de democracia adotadas são formais, institucionais. Governo, governança e suas dimensões de institucionalidade se promovem acima e apartados da sociedade (civil) - está se coloca no papel de consertar as fissuras do instituído sob uma perspectiva gerencial, ou no papel de se contrapor/exigir/pressionar ou, ainda, de participar do Estado e, assim, controlá-lo.

Mais recentemente, alguns estudos vêm ressaltando a importância de ampliar o olhar sobre as relações entre Estado e sociedade civil, rediscutindo a naturalização dessa dualidade fundadora (Ansel, 2011; Brandsen, Trommel, \& Verchuere, 2017; Frega, 2019; Lavalle \& Szwako, 2015; Sabel, 2012; Sabel \& Zeitlin, 2012). Tais estudos lançam pistas para reinterpretar a sociedade civil como um espaço intrínseco e constitutivo do Estado democrático e da ação pública promovida por este. Desse modo, a ação pública não se limita à ação governamental nem àquilo que o Estado determina/ atribui/controla; ela teria uma autonomia relativa, sendo promovida in loco e na interseção - entre o instituído e a autonomia social -, das associações, das interfaces socioestatais e das respostas coconstruídas para os problemas públicos. 
Dialogando com a óptica pragmatista e com o trabalho fundador de John Dewey (1927), os estudos citados desnaturalizam, assim, a noção clássica de Estado, buscando aproximar as dimensões de representatividade e de legitimidade, típicas da ideia de governo, da dimensão da resolução de problemas públicos (governança). Como discute Ansell (2011), essa aproximação implica ampliar a interpretação sobre como funcionam a administração pública, as instituições e a própria democracia. Isso significa, como propõem Lavalle e Szwako (2015), considerar a codeterminação do Estado e da sociedade civil, focando nas dinâmicas e nas lógicas que constituem, de modo dinâmico e recíproco, essas interações socioestatais.

Por conseguinte, essa interconexão entre sociedade civil e Estado se torna central para conceber uma governança experimentalista (Sabel \& Zeitlin, 2012, p. 3) necessária num mundo onde a complexidade dos problemas públicos exige constante readaptação. Segundo os autores, a governança experimentalista se refere a um "processo recursivo de definição provisória de objetivos e sua redefinição constante, com base em aprendizado colaborativo". Tal forma de governança é colocada como uma poliarquia deliberativa direta. ${ }^{7}$ Deliberativa porque aberta ao argumento, ao questionamento e à reconsideração de definições e práticas antes estabelecidas. Poliarquia porque, na ausência de um decisor final e central, os diversos atores que compõem os sistemas de governança têm de aprender e definir seus objetivos no enfrentamento dos problemas com base na relação com os demais.

$\mathrm{Na}$ medida em que enfrentam, aprendem e agem sobre os problemas públicos, os coletivos da sociedade civil se constituem como públicos que compõem as arenas públicas, que são definidas por Cefaï (2012) ao mesmo tempo como espaços de confronto e de performance, nos quais a ação pública se situa. Portanto, o público deixa de ser monopólio do Estado e a construção democrática se torna algo a ser investigado, acompanhado, visando dar luz aos fatos públicos enquanto estes estão sendo gerados. Observando as arenas públicas, pode-se compreender melhor como os atores enfrentam e se comprometem num esforço coletivo de definição e de controle dessas situações tidas como problemáticas, bem como os efeitos disso.

Ao discutir mais detalhadamente as possibilidades desse processo de reinvenção das democracias diante do cenário atual, Frega (2019) traz importantes pistas para esse debate. O autor recoloca a questão da crise das democracias liberais, buscando evidenciar que essa crise não é apenas procedimental ou de esvaziamento de sua substância participativa. Segundo ele, para construir novas vias alternativas a fim de superar essa crise, tanto conceitualmente quanto na prática, é importante que possamos repensar e reconstruir a democracia para além de seu aspecto formal, visto como uma combinação de instituições que traduzem os anseios populares na política. Isso significa considerar as potencialidades dos diversos padrões de interação social que a compõem como fontes de ação criativa, de inovação social e de transformação do instituído.

Frega (2019) explora o potencial das experimentações democráticas, entendidas como possibilidades de transformação do instituído essenciais para reinventar a democracia. Como destaca o autor, o experimentalismo democrático fornece insights teóricos e analíticos para compreender como a democracia se relaciona com a inovação social. Para além de identificar e discutir os alcances e os limites dos processos participativos, trata-se de compreender de que maneira ocorre o design do instituído - por meio do enfrentamento, pelos diferentes públicos -, das consequências indesejáveis

${ }^{7}$ Para uma discussão mais abrangente sobre esse conceito, ver Cohen e Sabel (1997). 
da vida em comum. A palavra "experimentação" remete à busca de soluções mais inovadoras, ao exercício do questionamento e aos testes, num viés de diminuição dos erros em resposta às situações problemáticas enfrentadas, que são sempre contextualizadas. Já a palavra "democrática" se relaciona aos processos de colaboração e aprendizado mútuo, por meio da participação e da valorização de diversas formas de conhecimento e saberes, em especial das pessoas afetadas. Esse processo de aprendizagem coletiva e evolutiva, baseado na investigação pública, se apresenta aos autores como importante elemento de revitalização da ação pública e das democracias na atualidade.

Nessa mesma linha, Brandsen, Trommel, e Verchuere (2017) discutem que esses processos podem possibilitar uma reinvenção da sociedade civil e de sua forma de atuação na esfera pública, transpondo a dicotomia entre relações de adversários ou relações colaborativas com o Estado.

Segundo os autores, entre a lógica institucional do Estado e a nova dinâmica social emergente no âmbito local "se desenvolvem colaborações entre atores que têm um pé no velho mundo - burocratas, gestores públicos, políticos locais, organizações de interesse etc. - e o outro no campo social emergente. O valor abrangente que une esses atores pode ser caracterizado como uma busca orientada por problemas de artesanato público" (Brandsen, Trommel, \& Verchuere, 2017, p. 687).

Diante dessa problematização e considerando o cenário turbulento e indeterminado imposto pela pandemia da COVID-19 no Brasil - com problemas públicos cada vez mais urgentes e complexos que podem perdurar para além da pandemia - é que buscamos compreender a atuação da sociedade civil, suas características e sua influência na ação pública, numa perspectiva de promoção de experimentações democráticas. A seguir, entramos nessa análise.

\section{MOBILIZAÇÃO DA SOCIEDADE CIVIL FRENTE À PANDEMIA DA COVID-19 NO BRASIL}

A mobilização da sociedade civil para o enfrentamento da pandemia no Brasil ocorreu desde o início e tem sido relevante, como demonstram os dados coletados em relatórios e levantamentos analisados nesta pesquisa. Um dos mais completos se refere ao mapeamento de iniciativas contra a COVID-198 realizado de forma colaborativa pela organização PonteAPonte que teve início em março. Tal mapeamento mostrou que, 2 meses após o primeiro caso registrado no país, já existiam centenas de iniciativas da sociedade civil combatendo os efeitos indesejáveis da pandemia, envolvendo atores do investimento social privado (ISP), OSCs, movimentos sociais, coletivos das (e nas) próprias comunidades e iniciativas promovidas por negócios sociais ou de impacto.

No fim de abril, o mapeamento já contava com 450 ações cadastradas. Os dados recolhidos foram então sistematizados num relatório ${ }^{9}$ e confirmados pela análise de outros mapeamentos realizados por instituições representativas do campo, como o Grupo de Instituto Fundações e Empresas (Gife), ${ }^{10}$ a Associação Brasileira de Organizações Não-Governamentais (Abong), ${ }^{11}$ o Instituto Marielle Franco e

\footnotetext{
${ }^{8}$ Mapeamento colaborativo. Recuperado de https://docs.google.com/spreadsheets/d/1spIFsibSNv42B2eBBpZPH5L9qYhSiS48SoSTG 8 sWHmE/edit\#gid=892611875

${ }^{9}$ Relatório Os primeiros 60 dias de COVID-19 no Brasil em 60 fatos, reflexões e tendências em filantropia, investimento social e no campo de impacto social. Recuperado de https://drive.google.com/file/d/14eHc2LhhoGbAaZaf46Aa5fe3iGbeQUzl/view

${ }^{10}$ A plataforma Emergência COVID-19, desenvolvida pelo Gife, enfoca as ações promovidas pelo ISP, mas inclui também fundos e campanhas comunitárias ou públicas, assim como guias e ferramentas. Recuperado de https://emergenciacovid19.gife.org.br/

${ }^{11}$ A plataforma da Abong denominada \#RedeSolidaria tem por foco promover o engajamento, a doação, e divulgar as ações promovidas pela sociedade civil. Recuperado de https://www.engajar.redesolidaria.org.br/
} 
o Favela em Pauta, ${ }^{12}$ os quais podem ser acessados na plataforma Sociedade Contra o Corona, ${ }^{13}$ que congrega cerca de 160 movimentos sociais, organizações e coletivos da sociedade civil brasileira. A análise desses levantamentos nos permite tecer algumas considerações e construir um panorama da atuação da sociedade civil brasileira nesse cenário.

Quanto às formas de atuação, em sua maioria, as ações coletivas promovidas se referem a campanhas de arrecadação de dinheiro ou de doações in natura, seja para assistência social - com foco na distribuição de alimentos e de itens de higiene e limpeza -, seja para saúde, com a compra de equipamentos de proteção e para hospitais. A análise de tais campanhas permite constatar uma pulverização e que muitas são lideradas por atores já protagonistas, sobretudo da filantropia empresarial, ou por OSCs e coletivos que apoiam comunidades periféricas e/ou grupos específicos. Embora em menor número, há também campanhas realizadas pela articulação de diferentes atores e setores - a exemplo da União Rio ${ }^{14}$ e da União São Paulo, ${ }^{15}$ iniciativas de grupos ligados ao ISP -, bem como ações coletivas nas comunidades, como a Frente de Mobilização da Maré16 ou a campanha COVID-19 nas Favelas, ${ }^{17}$ realizadas pelos próprios movimentos e por coletivos das periferias.

Essas articulações são evidentes também entre atores intermediários desenvolvedores do campo, dando origem a novas formas de promover ação coletiva, a exemplo da criação de plataformas on-line colaborativas, muitas das quais serviram de fonte para este estudo. Tais iniciativas têm produzido efeitos relevantes, como a coprodução de novas informações e conhecimento para o campo, o debate e a troca de experiências por webnários e outros meios on-line, a produção de manifestos, entre outros movimentos. Isso aponta para outras formas de atuação e consequências para além da resposta às emergências.

No que se refere aos protagonistas, destaca-se a atuação dos atores do ISP, liderado por institutos, fundações e empresas, responsáveis por grande parte do investimento, das iniciativas (57) e de fundos e campanhas (69) mapeados pelo Gife na plataforma Emergência COVID-19.

A análise desses dados permite visualizar também a importância da mobilização das próprias comunidades periféricas, como é o caso das ações promovidas pela Central Única das Favelas (Cufa) ${ }_{1}^{18}$ não só para arrecadação de recursos, mas na promoção da saúde, na prevenção do contágio, na mobilização de voluntários, entre outros. De igual maneira, destacam-se as campanhas solidárias promovidas por ONGs e movimentos sociais voltados para grupos específicos como indígenas, quilombolas, catadores etc. Na plataforma \#Rede Solidária, desenvolvida pela Abong, mais de 40 iniciativas como essas são mapeadas. Esses movimentos têm tido um importante papel em dar luz às condições de vida, às demandas e às vulnerabilidades de grupos e populações muitas vezes invisíveis para as políticas públicas.

Quanto ao investimento de recursos monetários, o total doado para o combate a COVID-19 no início de junho de 2020 - segundo o monitor de doações desenvolvido pela Associação Brasileira de

\footnotetext{
${ }^{12} \mathrm{O}$ Mapa Corona nas Periferias, uma iniciativa do Instituto Marielle Franco e do Favela em Pauta, constitui-se num mapeamento para dar visibilidade às iniciativas de combate a COVID-19 em favelas e periferias do Brasil. Recuperado de https://www.institutomariellefranco. org/mapacoronanasperiferias

${ }^{13}$ Recuperado de https://www.sociedadecontraocorona.org/

${ }^{14}$ Para saber mais, ver https://www.movimentouniaorio.org/

${ }^{15}$ Para saber mais, ver https://www.uniaosp.org/

${ }^{16}$ A frente foi constituída no dia 19 de março. O objetivo inicial era fomentar ações que levassem informação aos moradores das 16 comunidades da Maré. Atualmente, é formada por cerca de 140 mil pessoas e promove diversas ações de mobilização sobre a importância de se proteger, de garantir hábitos de higiene e de respeitar o isolamento social. Para saber mais, ver https:/www.frentemare.com/

${ }^{17}$ Para saber mais, ver https://www.covid19nasfavelas.meurio.org.br/\#block-14403

${ }^{18}$ Para saber mais, ver https://www.facebook.com/cufabr/
} 
Captadores de Recursos (ABCDR $)^{19}$ - era de R $\$$ 5.545.031.943. Desse total, 83\% foram doados por empresas; $7 \%$, por campanhas e lives; $5 \%$, por indivíduos e famílias; e $2 \%$, por fundações, institutos filantrópicos ou igrejas. A evolução das doações, expressa na Figura 1, a seguir, demonstra um contínuo aumento da quantidade doada e do número de doadores, o que indica que a situação de emergência trazida pela pandemia estimulou a cultura e a prática da doação no país.

FIGURA 1 EVOLUÇÃO DAS DOAÇÕES PARA O COMBATE A COVID-19 PELA SOCIEDADE CIVIL

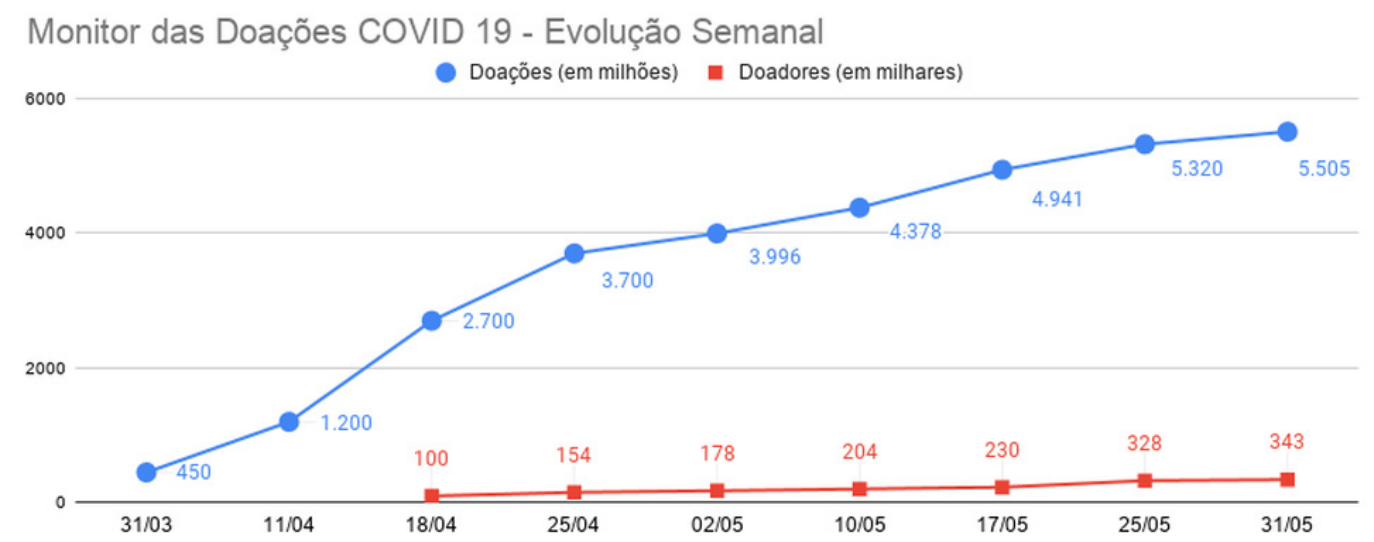

Fonte: Associação Brasileira de Captadores de Recursos (2020).

Quanto à abrangência das ações, todos os mapeamentos demonstram maior concentração da atuação da sociedade civil nas regiões Sudeste do país, sobretudo nas cidades do Rio de Janeiro e de São Paulo. Assim, frisa-se a importância de irradiar a atuação e o investimento social para zonas mais recônditas do Brasil e para municípios com maior vulnerabilidade no enfrentamento da pandemia, evitando a concentração de recursos e das ações.

Os dados analisados não são exaustivos, mas já sinalizam a relevância da atuação da sociedade civil no combate aos efeitos da COVID-19 no Brasil, seja no investimento de recursos financeiros, seja na mobilização de expertises e/ou na construção coletiva de respostas para o enfrentamento dos efeitos da pandemia, sobretudo junto às populações mais vulneráveis. Os resultados revelam que a atuação mais comum tem sido na urgência e ocorre majoritariamente de forma pulverizada, sendo mais expressiva nos campos da assistência social e da saúde, principalmente no Sudeste, lideradas por atores já protagonistas. Isso indica que a situação de pandemia potencializa regimes e lógicas de ação preexistentes no campo já sinalizadas por estudos precedentes (Dagnino, 2002; Landim \& Scalon, 2000) e pelos mapeamentos nacionais como os das Fundações privadas e associações sem fins lucrativos (Fasfil) e o mapa das OSCs. ${ }^{20}$ Essas análises mostram que, historicamente e até hoje, o campo das OSCs no país é marcado por uma matriz assistencialista, com predomínio de organizações

\footnotetext{
${ }^{19}$ Recuperado de https://www.monitordasdoacoes.org.br/

${ }^{20}$ Os dados da Fasfil 2010 (Abong et al., 2012) e do mapa das OSCs (Recuperado de https://mapaosc.ipea.gov.br/) demonstram que a maior parte das associações e das fundações brasileiras estão concentradas no Sudeste, são religiosas e/ou atuam nos campos de educação, saúde e assistência social. De igual modo, revelam que, na última década, tais organizações vêm se politizando e dividindo espaço com aquelas que atuam na defesa de direitos.
} 
religiosas e que prestam serviços nos campos de assistência social, educação, saúde, esporte e lazer, num prisma de complementaridade ao Estado.

Embora em menor número, os resultados permitem identificar iniciativas que vão além da urgência e indicam novos regimes de governança, engajamento e mobilização na esfera pública, envolvendo ou não recursos financeiros. Destaca-se, nesses casos, o protagonismo das próprias comunidades periféricas, que criam seus fundos, estabelecem canais para tornar públicos seus problemas, denunciam abusos e produzem as próprias críticas e pesquisas, o que tem provocado mudanças interessantes na paisagem do campo e importantes efeitos na governança da crise.

A atuação no combate à pandemia tem aberto espaço para uma certa "reinvenção da sociedade civil" e para emergência de experimentações e inovações sociais, ainda que essas não sejam a regra. Mas, fazendo uma ponte com a discussão teórica precedente, em que medida esse movimento vai além de experiências pontuais e pode ser gerador de experimentações democráticas? Qual é sua interface com a governança e com as políticas públicas? Que aprendizados podem ser gerados com isso? Para avançar em elementos de resposta a essas questões, relacionamos os achados em escala nacional com a realidade da cidade, laboratório no qual a ação pública ocorre. Para isso, examinamos a situação da arena pública de enfrentamento da pandemia da COVID-19 em Florianópolis, a qual acompanhamos mais de perto, por meio de pesquisa de campo.

\section{ANALISANDO MAIS DE PERTO A ATUAÇÃO DA SOCIEDADE CIVIL NA CIDADE: 0 CASO DE FLORIANÓPOLIS}

Assim como evidenciado em escala nacional, a análise da arena pública de enfrentamento da pandemia em Florianópolis mostrou que a mobilização da sociedade civil fez diferença na resposta aos efeitos da crise na cidade. Essa importância se amplia diante da demora da liberação da renda emergencial aprovada pelo Congresso e da carência em termos de governança e das respostas oferecidas pelas políticas públicas municipais, especialmente a política de assistência social que atende às populações mais vulneráveis. ${ }^{21}$

Florianópolis, apesar de ter o terceiro maior Índice de Desenvolvimento Humano (IDH) do Brasil, conta com 67 zonas de interesse social nas quais vivem 123.239 pessoas ( $24,6 \%$ da sua população) em situação de extrema pobreza, ganhando até meio salário mínimo por mês (Instituto Brasileiro de Geografia e Estatística [IBGE], 2010). No início da pandemia, a cidade liderava o número de casos confirmados da COVID-19 no estado, e atualmente (final de julho) é a quinta cidade catarinense e a primeira da macrorregião da Grande Florianópolis, contabilizando 2.754 casos diagnosticados e 41 mortes por coronavírus.

A cartografia da arena pública feita pela pesquisa possibilitou identificar 44 iniciativas ${ }^{22}$ promovidas por atores da sociedade civil para o combate aos efeitos da pandemia da COVID-19. A maioria (38) é protagonizada por atores que já atuavam no ecossistema de inovação social (EIS) da cidade. A rede

\footnotetext{
${ }^{21}$ Até início de abril a prefeitura tinha promovido ações de suporte às famílias mais vulneráveis, como a implantação de um cartão merenda de $\mathrm{R} \$ 100,00$ mensais para 2.457 crianças matriculadas nas escolas municipais e de um cartão de $\mathrm{R} \$ 100,00$ mensais para 1.226 profissionais autônomos. Além disso, foram distribuídas 3 mil cestas básicas por meio da Rede Somar, rede de voluntariado presidida pela primeira-dama do município. Além de insuficientes para cobrir a demanda, os Centros de Referência de Assistência Social (CRAS e CREAS) foram fechados, e o atendimento passou a ser feito por telefone e on-line, o que dificultou o acesso das famílias a esses benefícios. ${ }^{22} \mathrm{~A}$ lista das iniciativas e suas características está disponível na plataforma on-line da pesquisa. Para acessar, ver http://www.observafloripa. com.br/is-page//publicProblemsDetails?id=57
} 
formada pelas iniciativas mapeadas, observadas e acompanhadas, ${ }^{23}$ bem como seus atores de suporte, está ilustrada na Figura 2 a seguir.

Do total mapeado, 90\% (40) são campanhas de arrecadação para compra e doação de cestas básicas e material de higiene, sendo a maioria para as famílias já atendidas pelas OSCs (associações em sua maioria). Onze são promovidas por coletivos ou movimentos sociais, visando atender a grupos específicos como indígenas, quilombolas, população de rua, idosos e estudantes em vulnerabilidade. Apenas 9 são promovidas por articulações mais amplas, seja pela relação entre poder público e sociedade civil, seja pela parceria entre universidade e sociedade civil, ou mesmo pelo envolvimento de mais de 1 organização/ movimento da sociedade civil. Assim, destaca-se o papel de organizações intermediárias reconhecidas e que já atuavam no papel de articuladores na rede do EIS, a exemplo do Instituto Vilson Groh (IVG), destacado na Figura 1, e do Instituto Comunitário Grande Florianópolis (Icom).

\section{FIGURA 2 REPRESENTAÇÃO DA REDE DE INICIATIVAS E SEUS APOIADORES NO COMBATE À COVID-19 EM FLORIANÓPOLIS}

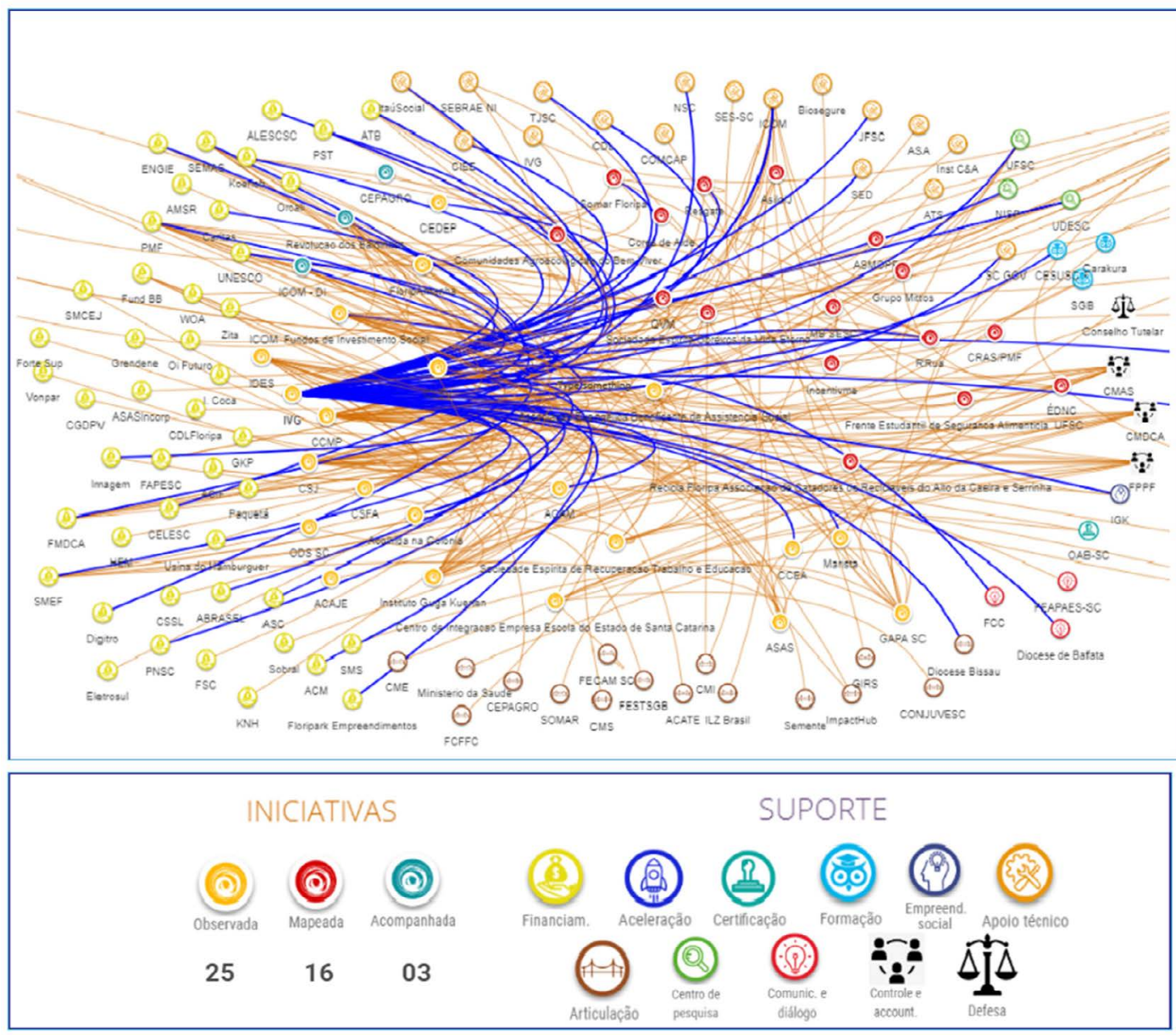

Fonte: Pesquisa de campo.

\footnotetext{
${ }^{23}$ Iniciativas acompanhadas são aquelas que estão sendo pesquisadas sistematicamente pela equipe do observatório. Iniciativas observadas são aquelas que tiveram todas as informações do questionário complementadas e validadas pela equipe. Iniciativas mapeadas são aquelas identificadas por indicação ou autocadastradas na plataforma.
} 
Olhando mais de perto para essa arena pública, percebe-se que as iniciativas, em sua maioria, seguem o padrão da realidade nacional, explorada acima, promovendo ações de assistência social a famílias e comunidades que já atendiam antes da pandemia. Essa atuação tem grande relevância diante do gap de respostas governamentais e da urgência, como exposto. Mas, indo além das ações emergenciais, qual é o potencial para promoção de experimentações democráticas dessa rede? Diante dessa questão, é importante explorar algumas experiências acompanhadas pela pesquisa, nas quais foram observadas maior articulação e incidência em termos de resultados e na ação pública.

Uma primeira experiência se refere ao Fundo de Apoio Emergencial COVID-19 do Icom, associação que atua como uma fundação comunitária na região da Grande Florianópolis e foi criada em 2005 na cidade por um grupo de lideranças femininas que já atuavam nos campos do ISP e da sociedade civil da cidade. No início do isolamento social, na segunda semana de março, o Icom destinou um dos fundos existentes para apoio às famílias em vulnerabilidade social por meio de doação de cestas básicas. No fim de março, a OSC recebeu um aporte de R 500 mil da Fundação Itaú Social, o que levou a constituição de um comitê consultivo para o fundo formado por experts e lideranças comunitárias, resultando na proposta de criação de um banco comunitário e de uma moeda social, experiência pioneira na região Sul.

O banco tem sido implementado pela parceria entre o Icom e OSCs inseridas nas comunidades, as quais são correalizadoras, e funciona por meio da criação e da circulação de uma moeda social que é utilizada pelas famílias participantes para a compra de alimentação e produtos de higiene em mercados e comércios locais por 3 meses. Essa etapa-piloto está sendo implementada em 3 comunidades: Serrinha, Chico Mendes e Monte Serrat. O fundo mobilizou até agora (junho de 2020) 294 investidores sociais, incluindo pessoas físicas e jurídicas, que doaram um total de $\mathrm{R} \$ 666.272,00$ e apoiaram 931 famílias e 21 OSCs, com a doação de cestas básicas. O banco, por sua vez, beneficiou até então 502 famílias, 3 OSCs e 16 comércios locais nas comunidades envolvidas (Icom, 2020). A proposta é dar continuidade à experiência do banco comunitário. Para tanto, vem sendo feitas parcerias com outras OSCs e comunidades locais e uma articulação com a rede de bancos comunitários do Brasil.

Uma segunda experiência se refere à Rede com a Rua, constituída por 16 grupos/coletivos/ associações que desenvolvem ações junto às pessoas em situação de rua na cidade. Essa rede já existia antes da pandemia, e seus integrantes se reuniam semanalmente com a população de rua para debater uma estratégia de instalação de um centro de atendimento voltado para esse público. Com a pandemia, e diante da ausência de um plano emergencial da prefeitura para essa população, esses coletivos passaram a atuar de forma conjunta, constituindo a rede, que se encontra atualmente em processo de formalização.

Em articulação com a secretaria de assistência social, a Rede com a Rua concebeu e implementou uma estratégia para distribuição de 3 refeições por dia na Passarela do Samba Nego Quirido, para cerca de 300 pessoas em situação de rua. A rede realiza também um mutirão de cadastro dos usuários para recebimento do auxílio emergencial, entrega de refeições e doações àqueles que não acessam a passarela. Para além dessa atuação, a Rede com a Rua tem tido um papel central na construção de uma agenda propositiva e de mobilizações para fazer avançar as políticas públicas em relação à temática. Entre as propostas, destacam-se a implementação de um restaurante popular na cidade, a criação de novas alternativas de moradias populares e a questão da abordagem em relação à população de rua - todas elas detalhadas num posicionamento público assinado pela rede em 25 de abril (Associação Rede Rua, 2020). 
Por fim, ressalta-se a articulação promovida pela Rede IVG junto às comunidades do Maçico do Morro da Cruz. O IVG foi criado em 2011 como forma de potencializar a atuação e a articulação entre as diversas organizações apoiadas pelo padre Vilson Groh, líder comunitário histórico da cidade. Hoje, a Rede IVG é composta por 6 OSCs, além de trabalhar em parceria com o Grupo Marista, por meio das unidades do Centro Educacional Marista São José e Centro Educacional Marista Lucia Mayvorne (que funciona no Monte Serrat e é gratuito). A atuação da Rede IVG ocorreu também desde o início da pandemia, com a criação do fundo emergencial de apoio às comunidades empobrecidas do IVG. Até junho de 2020, foram mobilizados e investidos $\mathrm{R} \$ 278.539,11$, além de doações que resultaram em 6.290 cestas básicas mais kits de higiene e limpeza distribuídos nas comunidades onde a rede IVG atua.

A atuação, porém, não se limita a isso. Destaca-se a mobilização que resultou na carta aberta apoiada por várias outras OSCs e movimentos da cidade intitulada Nossas Vidas Importam. ${ }^{24}$ Nessa carta são levantadas diversas demandas de comunidades e OSCs da Grande Florianópolis, como: problemas de acesso aos CRAS que estão fechados e funcionando remotamente; dificuldades com o cadastro único, com o auxílio emergencial e para recebimento dos benefícios eventuais da assistência social; vulnerabilidades dos imigrantes; aumento de violência doméstica e da violência policial nas comunidades.

A partir dessas demandas, a carta finaliza com a seguinte solicitação: "Diante desses apontamentos é portanto urgente que os gestores públicos na forma de lei apresentem um plano de enfrentamento da pandemia [...] Para tanto sugerimos a criação de uma mesa de crise que una representantes das secretarias municipais de saúde e assistência social e das oscs que estão presentes na ponta no enfrentamento à situação de pandemia e também a criação de comitês locais que promovam essa articulação intersetorial e o diálogo com as lideranças comunitárias" (Nossas vidas importam, p. 4).

Essas iniciativas têm em comum a mobilização de diferentes atores, suas redes, recursos e saberes preexistentes em torno da cocriação de comunidades de experimentação que problematizam, debatem, denunciam e agem, fomentando novas respostas para a situação de crise. Isso tem proporcionado a criação de novas formas de coordenação e a invenção de novas institucionalidades para enfrentamento das consequências indesejáveis da crise. Porém, olhando para sua interface com a ação pública, vemos que tais experimentações enfrentam desafios cotidianos que podem limitar seu alcance.

Um primeiro desafio observado se refere à comunicação e ao diálogo entre as iniciativas emergentes, o poder público e as políticas públicas. Desde o início do isolamento social na cidade, como mencionado, a posição da prefeitura foi a de realizar muitas das ações de assistência social por meio da Somar Floripa, ${ }^{25}$ rede de promoção de voluntariado criada pela prefeitura para conectar doadores e voluntários com as OSCs da cidade, coordenada pela primeira-dama do município. Por meio da campanha \#Somando contra a COVID-19, que utiliza o Fundo da Defesa Civil do município, a Rede Somar se tornou a principal protagonista, articuladora de doações e canal de comunicação da prefeitura com as OSCs, as comunidades e as populações mais vulneráveis da cidade. ${ }^{26}$ Isso fez com

\footnotetext{
${ }^{24}$ Ver em https://www.redeivg.org.br/noticias/nossas-vidas-importam/

${ }^{25}$ Para mais informações, ver http://somarfloripa.com/home/

${ }^{26}$ No início da pandemia na cidade, a primeira-dama divulgou um vídeo nas redes sociais solicitando doações e argumentando que "as campanhas precisam vir de entidades idôneas com prestação de contas transparente" e que "as duas únicas que não cobram taxa administrativa e estão autorizadas oficialmente a captar recursos" eram as contas bancárias do Fundo Municipal de Emergência da Defesa Civil de Florianópolis (Fundec) e da empresa Empreenda Social, parceira da prefeitura. A mensagem gerou muitas polêmicas e resultou numa nota pública assinada por várias OSCs afirmando a importância da atuação da sociedade civil organizada em situações de emergência e de crise.
} 
que não houvesse uma articulação maior das ações promovidas pela prefeitura e os próprios servidores e instrumentos do Sistema Único de Assistência social (Suas) do município, principalmente CRAS, nem com as OSCs mais atuantes, já que a atuação da Somar é muito controversa e questionada no campo da sociedade civil e também entre os servidores públicos do município. Irregularidades nesse protagonismo da Somar, em ano eleitoral, têm sido investigadas pelo Ministério Público de Contas e pelo Ministério Público de Santa Catarina. ${ }^{27}$

Por conseguinte, isso remete a outro desafio: a falta de atuação do poder público e dos instrumentos de políticas públicas, como promotores de articulação e de diálogo com as ações promovidas pela sociedade civil organizada, impedindo a construção de uma agenda comum e de uma governança compartilhada. Isso faz com que prevaleça uma lógica do "proprietário do problema público" (Gusfield, 1982), dificultando uma maior colaboração, uma articulação intersetorial e um diálogo mais amplo do poder público com as iniciativas emergentes e dessas entre si. Os problemas gerados por essa ausência de governança têm sido sentidos, discutidos, e são manifestados explicitamente na carta Nossas Vidas Importam, conforme citado acima, a qual estimulou outras mobilizações mais recentes para a criação de comitês intersetoriais de governança da crise na cidade e na região ${ }^{28}$.

Embora as intervenções sejam promovidas junto aos mesmos públicos e às mesmas situações problemáticas, a ausência de uma governança compartilhada pode gerar outro desafio, levando à dispersão de esforços e à não revisão e controle dessa atuação. Isso pode produzir efeitos de mimetismo nas ações, desestimulando a inovação, e gerar sobreposições e/ou competição, ou mesmo rivalidade, aumentando a desconfiança. As comunidades, por sua vez, acabam sendo mais beneficiárias de ações isoladas de assistência social do que sujeitos de direito de uma ação pública coconstruída. A assimetria e a desconfiança entre governo e sociedade civil, entre promotores e beneficiários, entre experts e as comunidades pode dificultar a produção de inovações sociais e sua integração nas políticas públicas. Tais questões se colocam como mais problemáticas diante da dimensão da crise provocada pela COVID-19 no país, no estado de Santa Catarina e na cidade de Florianópolis, com um aumento contínuo nos casos de contágio e nas mortes, causados, principalmente pela falta de uma governança mais efetiva e seus efeitos.

\section{CONCLUSÃo}

Essa devastadora crise provocada pela pandemia exige que tanto o governo quanto a sociedade civil se reinventem rapidamente, num contexto de ampliação de demandas e vulnerabilidades, no qual as respostas não podem ser fixadas a priori, as decisões envolvem processos abertos e as regras, para serem respeitadas, precisam ser construídas considerando a pluralidade de situações, interesses e atores envolvidos. Isso exige que se coloque em prática novas formas de governança para as quais a experimentação democrática pode ser inspiradora. Trata-se de criar espaços para que as inovações

\footnotetext{
${ }^{27}$ Ver detalhamento em https://folhacidade.com.br/2020/04/16/mpsc-e-mp-de-contas-cobram-explicacoes-da-primeira-dama-deflorianopolis-sobre-doacoes-para-ajudar-atingidos-pelo-coronavirus/

${ }^{28}$ Destaca-se aqui o ofício encaminhado pelo Fórum de Políticas Públicas de Florianópolis à Prefeitura de Florianópolis em junho, bem com a petição pública "Nossas Vidas, Nossas Vozes" assinada por mais de 1000 pessoas e encaminhada aos prefeitos da região solicitando a criação de comitês intersetoriais nos municípios e na Grande Florianópolis para governança da crise, como resultado da articulação entre grupos de pesquisa da UDESC e da UFSC, o FPPF e organizações da sociedade civil. Para saber mais, ver https://www.facebook. com/forumdepoliticaspublicasdeflorianopolis.
} 
sociais emergentes dialoguem entre si e com os poderes instituídos, produzindo uma renovação nas instituições e na ação pública, como discutido.

As evidências trazidas por este estudo exploratório, tanto no âmbito nacional quanto no caso de Florianópolis, permitem concluir que a atuação da sociedade civil diante da pandemia da COVID-19 tem feito diferença em termos de recursos mobilizados e de ações promovidas. Entretanto, quando observamos mais de perto essa atuação, percebe-se que ela tem se concentrado mais nas emergências, produzindo ações ainda pulverizadas nas áreas de assistência social e de apoio na saúde, sobretudo para populações e comunidades mais vulneráveis. Por outro lado, outras formas de ação coletiva emergem nesse cenário, gerando inovações sociais e abrindo espaço para novas práticas de governança pública.

Para que tais experimentações floresçam, parece necessário: (1) reforçar processos colaborativos de resolução das situações problemáticas trazidas pela pandemia, por meio de interações socioestatais e incluindo diferentes públicos, principalmente os afetados, na coconstrução das soluções e na apropriação de aprendizados e resultados gerados; (2) a articulação entre poderes emergentes e a inventividade da sociedade civil com a expertise, os instrumentos e os dispositivos das políticas públicas; (3) a ênfase na revisão, na aprendizagem pelo erro, nos testes, na transparência, na coprodução e no compartilhamento de informações e conhecimentos que possam produzir inteligência coletiva para enfrentamento da crise.

Em suma, torna-se central que os sistemas formais de governança da crise, sobretudo em âmbito local, estejam abertos para ver, aprender e atuar junto com as experimentações em curso nas redes da sociedade civil, muitas delas ainda invisíveis. Isso significa reforçar um necessário processo de democratização das políticas públicas (Frega, 2019), que não é algo que se atinge de uma vez por todas e resulta do engajamento contínuo nos desafios e nas controvérsias do fazer política cotidiano. Talvez seja cedo para dizer que as interações entre sociedade civil e Estado mudaram de forma significativa no país com a pandemia de COVID-19, mas sem dúvida se percebe que elas não serão as mesmas depois dessa crise. Assim, compreender "se" e "como" as novas interfaces entre sociedade civil e governo abrem espaço para possibilidades de reinventar nossa democracia, diante desse novo cenário, torna-se um tema central na agenda de pesquisa. 


\section{REFERÊNCIAS}

Abrucio, F. L., \& Teixeira, M. A. C. (2020). Formação para uma administração pública faz diferença. Folha de S. Paulo. Recuperado de https://www1.folha.uol. com.br/opiniao/2020/06/formacao-para-uma-boaadministracao-publica-faz-diferenca.shtml

Almeida, D. R. (2014). Pluralização da representação política e da legitimidade democrática: lições das IPs no Brasil. Opinião Pública, 20(1), 96-117.

Andion, C., Alperstedt, G. D., \& Graeff, J. F. (2020). Ecossistema de inovação social, sustentabilidade e experimentação democrática: um estudo em Florianópolis. Revista de Administração Pública, 54(1), 181-200.

Andion, C., Alperstedt, G. D., \& Graeff, J. F. (2019). Social Innovation Ecosystems and Cities: CoConstruction of a Collaborative Platform. In: J. Howaldt, C. Kaletka, A. Schröder, \& M. Zirngiebl (Eds.), Atlas of Social Innovation (2nd vol: A World of New Practices). Dortmund, Germany: TU Dortmund University, European School of Social Innovation.

Ansell, C. (2011). Pragmatist Democracy: Evolutionary Learning as Public Philosophy. Oxford, UK: Oxford Scholarship.

Associação Rede Rua. (2020). Posicionamento (mimeo). São Paulo, SP: Autor.

Brandsen, T., Trommel, W., \& Verschuere, D. (2017). The state and the reconstruction of civil Society. International Review of Administrative Sciences, 83(4), 676-693.

Cefaï, D. (2007). Pourquoi se mobilise-t-on? Les théories de l'action collective. Paris, France: La Découverte/Mauss.

Cefaï D. (2012). Qu'est-ce qu'une arène publique? Quelques pistes pour une approche pragmatiste. In D. Cefaï, \& I. Joseph (Eds.), L'Héritage du pragmatisme: conflits d'urbanité et épreuves de civisme. La Tour d'Aigues, Vaucluse: Éditions de l'Aube.

Chateauraynaud, F. (2011). Los tópicos ambientales: entre controversias y conflictos. Revista Colombiana de Sociologia, 34(1), 13-40.

Cohen, J.-L., \& Arato, A. (1994). Civil Society and Political Theory. Cambridge, UK: MIT Press.
Cohen, J.-L., \& Sabel, C. F. (1997). Directlydeliberative Poliarchy. European Law Journal, 3, 313-340.

Dagnino, E. (2002). Sociedade civil e espaços públicos no Brasil. Rio de Janeiro, RJ: Paz e Terra.

Dewey, J. (1927). The Public and Its Problems. Chicago, USA: Swallow.

Frega, R. (2019). Pragmatism and the wide view of democracy. Gewerbestrasse, Switzerland: Palgrave Macmillan.

Gaudin, J.-P. (2002). Pourquoi la gouvernance. Paris, France: Presses de Sciences Po.

Gusfield, J. R. (1982). Contested Meanings: The Construction of Alchool Problems. Wisconsin, USA: University of Winsconsin Press.

Instituto Brasileiro de Geografia e Estatística. (2010). As fundações privadas e associações sem fins lucrativos no Brasil (Estudos \& Pesquisas: informação econômica, 20). Rio de Janeiro, RJ: Autor.

Landin, L, \& Scalon, M. C. (2000). Doações e trabalho voluntário no Brasil. Rio de Janeiro, RJ: 7Letras.

Lavalle, A. G., \& Szwako, J. (2015). Sociedade civil, Estado e autonomia: argumentos, contraargumentos e avanços no debate. Opinião Pública, 21(1), 157-187.

Levi-Faur, D. (2012). The Oxford Handbook of Governance. Oxford, UK: Oxford University Press.

Mccarthy, J., \& Zald, M. (1977). Ressource Mobilization and Social Movements: a Partial Theory. American Journal of Sociology, 82(6), 1212-1241.

Meyer, M., \& Maier, F. (2015). The future of civil Society organisation governance: beyond managerialism. In J.-L. Laville, D. R. Young, \& P. Eynaud (Eds.), Civil Society, the Third Sector na Social Enterprise. London, UK: Routledge.

Sabel, C. (2012). Dewey, Democracy and Democratic Experimentalism. Contenporary Pragmatism, 9(2), 35-55.

Sabel, C., \& Zeitlin, J. (2012). Experimentalist Governance. In D. Levi-Faur (Ed.), The Oxford Handbook of Governance. Oxford, UK: Oxford University Press. 
RAP | Atuação da sociedade civil no enfrentamento dos efeitos da COVID-19 no Brasil

Salamon, L. M. (1995). Partners in Public Service: Government-Nonprofit Relations in the Modern Welfare State. London, UK: Johns Hopkins University Press.

Salamon, L. (2011). The New Governance and the Tools of Public Action: An Introduction. Fordham Urban Law Journal, 28(5), 1611-1674.
Tarrow, S. (2009). Opoderem movimento: movimentos sociais e confronto político. Petrópolis, RJ: Vozes.

Young, D. R. (2000). Alternative models of government-nonprofit sector relations: Theoretical and international perspectives. Nonprofit and Voluntary Sector Quarterly, 29(1), 149-172.

\section{Carolina Andion}

https://orcid.org/0000-0003-4723-3437

Pós-doutorado em Economia Social, doutora em Ciências Humanas Interdisciplinar e professora associada da Universidade do Estado de Santa Catarina. E-mail: andion.esag@gmail.com 